\title{
Effect of flattening wheat grain on grinding modes in roller mill
}

\section{Yevgen Kharchenko ${ }^{1}$, Andrii Sharan ${ }^{1}$, Olena Yeremeeva ${ }^{2}$}

\author{
1 - National University of Food Technologies, Kyiv \\ 2 - Uman National University of Horticulture, Uman
}

\section{Keywords:}

Wheat

Flaking

Milling

Gap

Rolls

\section{Article history:}

Received

30.09.2021

Received in

revised form

2.12.2021

Accepted

30.12 .2021

\section{Corresponding} author:

Yevgen

Kharchenko

E-mail:

a-537@ukr.net

\section{DOI:}

$10.24263 / 2310-$ 1008-2021-9-2-9

\section{Abstract}

Introduction. The flattening process is used to intensify the grinding of grain during varietal milling of wheat, while the optimal gap between the rolls of the ivy system remains uncertain.

Materials and methods. Flattening was carried out in a laboratory ivy machine with a roller diameter of $144.0 \mathrm{~mm} ; 68.4 \mathrm{~mm}$ and a rotation speed of $14.6 \mathrm{~s}^{-1}$. Grinding of wheat grain was carried out in a roller mill. The length of the rollers is $70 \mathrm{~mm}$; the number of rifts per $1 \mathrm{~cm}$ circle of rollers is 6 , the slope of the rifts is $12 \%$, the ratio of circular speeds is $1: 2$, the speed of rotation of the high-speed roller is $3.93 \mathrm{~m} / \mathrm{s}$, the diameter of the rollers is $150 \mathrm{~mm}$, the interdependence of the rifts is the back on the back, the angles of exacerbation of the rifts are $35^{\circ} / 70^{\circ}$. The mode of grinding wheat grain in the ivy machine and in the roller mill was determined by sifting the products obtained through a sieve with holes of $1.0 \mathrm{~mm}$. Granulometric analysis of crushed products was determined by sifting on a standard set of sieves with module $\Delta \approx 1.21$.

Result and discussion. When grinding ivy products in a roller mill, the total yield of intermediate products is nonlinear in nature and can be approximated by the equation of the second degree. The optimal distance between the rollers of the ivy machine is $1.4 \mathrm{~mm}$, provided that small products after flattening were previously isolated from the mixture of the flattened product.

The total product of intermediate products after flattening and grinding in the roller mill has a complex nonlinear nature, which did not allow to establish the optimal value of the gap value between the rollers of the ivy system. The total product of intermediate products obtained in total during flattening and grinding is $2.9 \%$ greater than the total product product yield obtained only in the roller mill with small ivy products previously removed.

Differential curves are polymodal and have 5 maximums. Integral curves have an S-shaped appearance. When grinding whole grain, the total yield of intermediate products is greater than when grinding flattened grain in a roller mill under the same conditions. When crushing flattened grain, a greater number of large fractions of products are formed due to small ones.

Conclusion. In the range of the established optimal clearance between the rolls of the flattening machine, there are no significant differences between the two methods of grinding wheat. 


\section{Introduction}

Intensification of the process of grinding wheat grain into flour is one of the urgent scientific problems, the solution of which is devoted to a large number of scientific works. (Dmitruk et al., 2013; Fistes et al., 2009; Mousia et al.,2004; Netrebsky, 2006; Warechowska et al., 2016).

The introduction of BUHLER technology in the twentieth century led to the failure of a number of technological methods of processing wheat grain into varietal flour. With a reduction in the technological process of grinding wheat grain into flour, it became necessary to find methods for intensifying the grinding process and increasing the output of finished products. (Kharchenko et al.,2016). One of these methods is the preliminary flattening of wheat grain before sending it into a dredged process (Morhun et al.,2010; Shutenko et al.,, 2014b).

Grain resistance to destruction is determined by complex processes that depend on the nature and condition of the grain, as well as the mode of mechanical load. The nature and condition of the grain should include such grain indicators as humidity, vitreity and size. The load mode must include the conditions of destruction: the size of the gap between the rollers, the surface of the rollers, the ratio of the circular speeds of the rollers, etc. (Dziki et al., 2012; Stefan et al., 2013; Voicu et al.,2013; Voicu et al.,2013).

Siberian V.A. and his collaborators, examining the process of flattening, concluded that the flattening of wheat grain before sending it to the first break system leads to a decrease in the yield of large grains with an increase in the degree of preliminary destruction of the grain, but recommendations on the size of the gap between the rollers of the ivy system were not provided. (Kharchenko et al., 2016; Shutenko et al., 2014a).

The main attention of many researchers was energy consumption during grinding and output of intermediate grinding products (Deineko et al.,2012; Kharchenko et al., 2016; Shutenko et al.,2014b). Despite the studies, a number of addictions remain undeseen. The main question that needs to be addressed is what should be the size of the gap between the rollers of the ivy machine to obtain the largest product of intermediate products in the roller mill I break system.

Odegov et al. (2004) recommends the gap value between the rollers of the ivy machine from 1.6 to $1.8 \mathrm{~mm}$, Perekopskyi \& Baranov (2004) recommends setting the gap value between the rollers $1.4 \mathrm{~mm}$. Afanasj'ev, Ostrykov \& Manujlov (2018) recommends for the use of flattened wheat, barley and sheep grain in feed production to set the gap value between the rollers of the ivy machine $0.5-0.6 \mathrm{~mm}$. Recommended by the researchers different values of the gap between the rollers of the ivy machine do not give an unequivocal recommendation of the distance between the rollers of the ivy machine when grinding wheat grain into flour. Researchers who studied the process of flattening did not pay attention to the issue of the need to isolate small products that are formed during the process of flattening. It is known that small grain grinding products affect the efficiency of the grinding process (Kharchenko et al., 2015).

Based on the analysis of scientific works, the purpose of the research was to establish the influence of the flattening process on the product of grinding products in the roller mill and to establish the optimal value of the gap between the rollers of the ivy machine. 


\section{Materials and methods}

\section{Grain preparing}

Before the start of research, wheat grain was cleaned in a laboratory grain cleaning separator in order to isolate small impurities, coarse and small grains. The purpose of this operation was also to align the grain to geometric dimensions. The grain cleaning separator used a set of lattice canvases with holes of $3.0 \times 20 \mathrm{~mm}, 2.4 \times 20 \mathrm{~mm}$ and $1.8 \times 20 \mathrm{~mm}$.

The grain fraction aligned in size was additionally passed through a laboratory aspiration channel with a width of $60 \mathrm{~mm}$ in order to isolate light impurities and partially pinched wheat grain. After that, the quality indicators of the experimental fraction of wheat grain were determined according to standard methods. In the prepared wheat determined the humidity, nature and glassiness of grain, as well as the mass of 1000 grains.

Before the flattening, wheat grain weighing $5 \mathrm{~kg}$ was poured into a container filled with a formula calculated according to the 1 (Kharchenko et al., 2018) amount of water. The final estimated moisture content of wheat was taken $15.0 \%$.

$$
G_{w}=G_{g}\left(\frac{W_{1}-W_{0}}{100-W_{1}}\right),
$$

where $G_{w}, G_{g}$ - accordingly, the mass of water and the mass of grain to be moistened; $W_{0}$, $W_{l}$ - accordingly the grain moisture content is initial and set $(W=15.0 \%)$.

After adding an estimated amount of water, the grain was actively mixed for $5 \mathrm{~min}$ and remained for a day for lag. Before flattening, the grain was additionally thoroughly mixed. Before the start of research, the weight of wheat grain was selected to determine the actual moisture content of the grain, and the rest of the wheat grain was sent for research. Of this grain mass, $1.0 \pm 0.1 \mathrm{~kg}$ of wheat was left for a control sample, which was crushed in a roller mill without flattening.

\section{Analysis of grain quality indicators}

The moisture content of the experimental wheat grain was determined in accordance with ISO 712:2009(E). «Cereals and cereal products. Determination of moisture content» (ISO, 2009a), by drying in a drying cabinet crushed in a laboratory mill the weight of wheat grain weighing $5 \mathrm{~g}$ for $60 \mathrm{~min}$. at a temperature of $130{ }^{\circ} \mathrm{C}$.

The bulk density of wheat grain was measured using a liter purquet PB-2 in accordance with ISO 7971-3:2009(E). «Cereals - Determination of bulk density, called mass per hektolitre» (ISO, 2009b). The measured mass of one liter of wheat grain was weighed on technical scales.

The mass of 1000 grains of wheat was measured in accordance with ISO 520:2010. "Cereals and pulses - Determination of the mass of 1000 grains" (ISO, 2010) by deducting 1,000 whole grains from the total mass of wheat grains.

The vitreousness of wheat grain was determined using the DSG-3 diaphanoscope (Olis, Odesa, Ukraine), by shining 100 grains of wheat with light rays. The vitreousness was determined in twelve reposts with the following calculation of the average value (Kharchenko et al., 2017).

After preparing wheat grain for flattening, it had the following quality indicators: initial grain moisture $-13.0 \pm 0.08 \%$; grain vitreousness $-21.3 \pm 4.7 \%$; nature of grain $-756.6 \pm 3,0$ $\mathrm{g} / \mathrm{l}$; weight 1000 grains $-38.0 \pm 0,6 \mathrm{~g}$. 


\section{Method of flattening and grinding}

To find out the effect of the flattening process on the process of grinding wheat grain in the roller mill, two research options were carried out.

In the first version of the studies, small products formed during the ivy process were selected in a laboratory aspiration channel with a channel width of $60 \mathrm{~mm}$, as shown in Figure 1.a, in order to isolate all small products (less than $1.0 \mathrm{~mm}$ ) and bring large ivy products to the same conditions. Purified products were sent to the roller mill for grinding.

In the second version of the study, all products formed in the process of flattening were sent to the roller mill without separation, as shown in Figure 1.b.

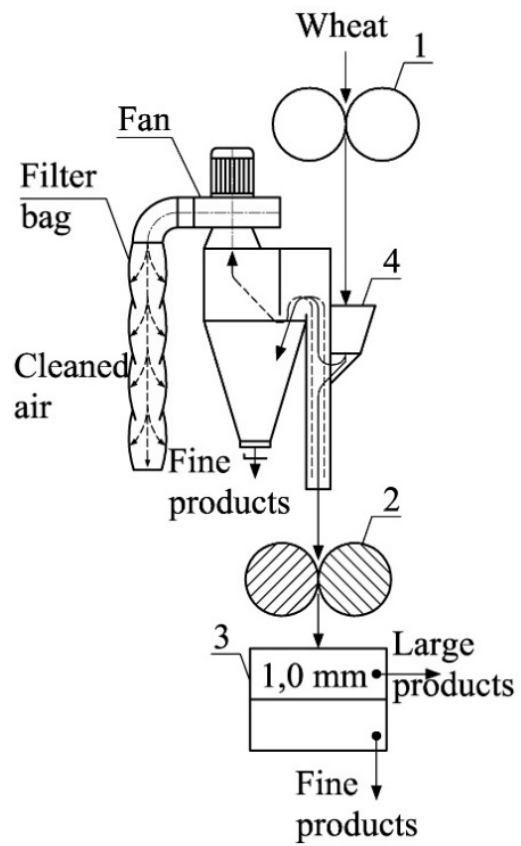

a

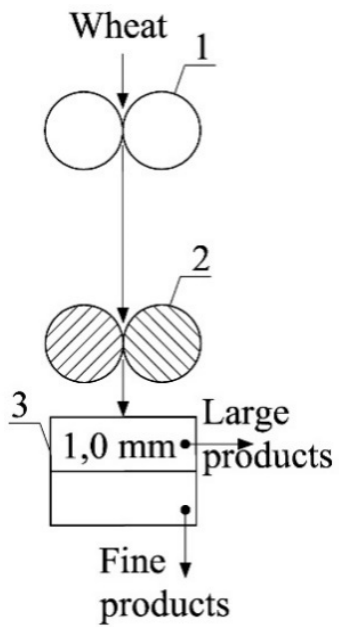

b

Figure 1. Schematic diagram of studies of the impact of flattening on the total product of intermediate grinding products:

1 - flacking mill; 2 - roller mill; 4 - control sieve; 4 - aspiration channel.

Flattening of wheat grain was carried out in four different modes, which were characterized by the distance between the rollers of the flaking mill. The distance between the rollers was measured using calibrated hand plates. The distance between the rollers was set from 0.4 to $1.6 \mathrm{~mm}$ in increments of $0.4 \mathrm{~mm}$ with a year of $0.4 \mathrm{~mm}$. The speed of rotation of the rollers of the flaking mill was $14.6 \mathrm{~s}^{-1}(880 \mathrm{rpm})$, the width of the rollers was $68.4 \pm 0.1$ $\mathrm{mm}$, and the diameter of the rollers was $144.0 \pm 0.01 \mathrm{~mm}$, the ratio of the circular speeds of the rollers was 1.0 .

Flaking products were crushed in the roller mill of the LM-2 laboratory unit (Elelmiszeripari Gepgyar, Budapest, Hungry) without changing the gap between the rollers. Grinding products were selected using a tray in four re-sieves, sifted on a metal-rolled sieve 
with holes of $1.0 \mathrm{~mm}$. The passage of the sieve was weighed and listed as a percentage. The amount of the product is allocated by the passage of a sieve of $1.0 \mathrm{~mm}$, expressed as a percentage determined the mode of grinding wheat grain in the roller mill.

Roller rollers had the following kinematic and geometric parameters: the length of the rollers $-70 \mathrm{~mm}$; the number of rifts per $1 \mathrm{~cm}$ circle of rollers is 6 , the slope of the rifts is $12 \%$, the ratio of circular speeds is $1: 2$, the speed of rotation of the high-speed roller is 3.93 $\mathrm{m} / \mathrm{s}$, the diameter of the rollers is $150 \mathrm{~mm}$, the interdependence of the rifts is dull to dull, the angles of exacerbation of the rifts are $35^{\circ} / 70^{\circ}$.

After sifting, the samples processed experimental data using Advanced Grapher software and made conclusions about changing the overall product and output of individual fractions of grinding products.

\section{Method of granulometric analysis}

After determining the total product, the products from the four repeats were combined and the granulometric composition of grinding products was determined. Granulometric analysis was carried out using a set of standard sieves with the condition that the sieve module was within $\Delta \approx \pm 1.21$ (Chornyi et al., 2021).

\section{Results and discussion}

\section{Effect of the gap value between the rollers of the flaking system on the product of intermediate flaking products}

Studies have found that the yield of products that are formed after flattening are nonlinear in nature and can be exproximed by the exponential equation. These results also confirmed the exponential dependence gained in the work (Kharchenko et al., 2016). The results of the research are shown in Figure 2.

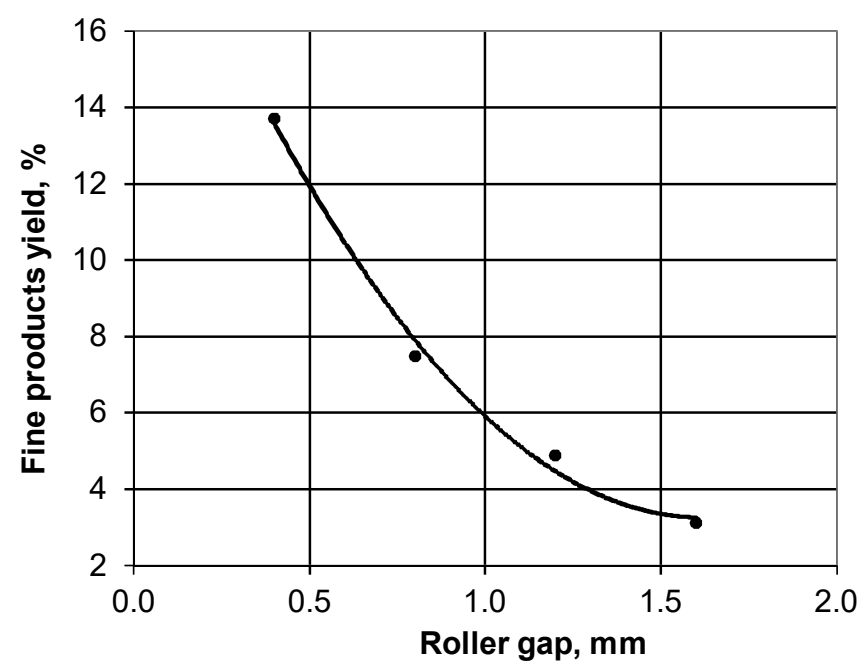

Figure 2. Yield of intermediate products obtained after flattening of wheat grain 


\section{- Food Technology -}

The curve can be aproximized by the following equation:

$$
Y=21,24 e^{-1,216 d}
$$

where $Y$ - the total output of intermediates after flattening, $\% ; d$ - the distance between the rollers of the ivy machine, $\mathrm{mm}$.

The standard error of experimental and calculated values is $0.49 \%$, and the correlation coefficient is 0.99 , indicating a strong relationship between the studied traits.

\section{Crushing of flattened wheat in roller mill and draped system with selected small products}

The results of studies have shown (Figure 3) that with an increase in the distance between the rollers of the ivy machine, the total yield of small grinding products after the roller mill increases by parabolic dependence, which can be described by the following equation:

$$
Y_{R m}=-7,18 x^{2}+20,42 x+32,7
$$

where $Y_{R m}$ - general output of grinding products after the roller mill, \%; $x$ - the distance between the rollers of the flaking system, $\mathrm{mm}$.

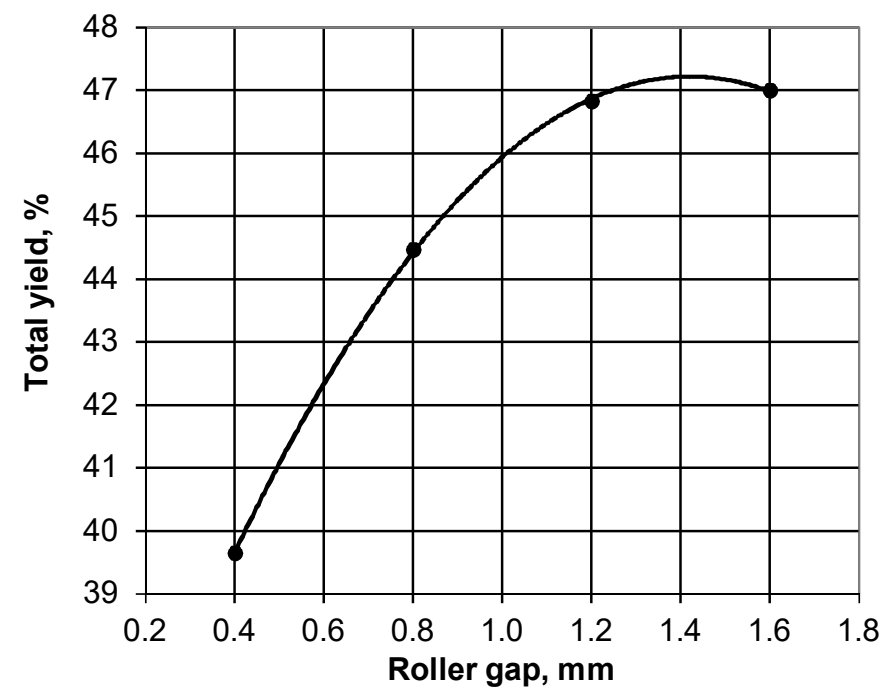

Figure 3. Effect of the distance between the rollers of the flaking system on the total output of grinding products (with selected products after the flaking mill)

The correlation coefficient is 0.99 , which indicates a strong connection of the studied signs. The standard deviation is $0.05 \%$.

This nature of the curve may be associated with the deformation of flattened wheat grain. At a distance between the rollers of $0.4 \mathrm{~mm}$ of the flaking mill, the greatest deformation of the grains occurs. When grinding such grains in the roller mill, the rollers will have less impact on the grain. With an increase in the size of the gap between the rollers of the ivy machine, the deformation of wheat grain will decrease, but when such wheat is crushed, the 


\section{— Food Technology-}

rollers of the roller mill will increase the impact on these grains. At the same time, the resulting small products do not affect the grinding process in the roller mill, because they are allocated in the aspiration channel.

The shape of the parabolic curve has an extremum, which allows you to determine the value of the distance between the rollers at which the largest yield of intermediate grinding products after the roller mill was observed.

By differentiating equation 3 and equating it to zero, we will get:

$$
\begin{gathered}
\frac{d Y_{R m}}{d x}=-7,18 \cdot 2 x+20,42 \\
-14,36 x+20,42=0
\end{gathered}
$$

Solving the equation (5) we obtain the value of the gap value between the rollers of the flaking system, in which the largest yield of intermediate grinding products after the roller mill was observed:

$$
x=\frac{20,4}{14,3}=1,42 \approx 1,4 \mathrm{~mm} .
$$

The optimal value of the gap between the rollers of the flaking mill, which observed the largest yield of intermediate products when crushing flattened wheat is $1.4 \mathrm{~mm}$.

\section{Crushing of flattened wheat together with small products in the roller mill of I break system}

When grinding in the roller mill of flattened wheat grain together with small fractions formed in the process of flattening, the nature of the dependence of the total yield of grinding products changes significantly. The curve of the total product of intermediate products of the two systems has a descending type. At the same time, the largest total product was observed at a gap value between the rollers of the ivy system of $0.4 \mathrm{~mm}$ and amounted to $63.5 \%$. An increase in the gap between the rollers of the flaking system from $0.4 \mathrm{~mm}$ to $1.6 \mathrm{~mm}$ led to a decrease in the total output by 13.6\%. The results of the research are given in Figure 4 .

The complex dependence of the total product of the two systems can be explained by the fact that powdery products after the flaking mill fall into the inter-shale gap and the break system and create additional resistance to the destruction of large staircase particles of the endosperm. At the stage of flattening, particles of different sizes are formed. In the composition of these mixtures there are particles of flour, dunsts and grains that do not require grinding. Left in the total mass of the product, together with large staircase particles of the endosperm, they assume part of the efforts of the rollers and the break system, reducing the energy consumption that should go to the destruction of the endosperm, thereby reducing the potential technological efficiency of the grinding process (Kharchenko et al.,2015).

In the roller mill, the gap between the rollers was constant $(0.5 \mathrm{~mm})$, which means that with a decrease in the deformation of the grains during grinding in the roller mill, the yield of small products will increase. Based on this, the nature of the curve on Figure 4, can be explained by the fact that in the range of gaps between the rollers of the ivy machine from 0.4 to $0.8 \mathrm{~mm}$, the yield of small products during flattening decreases much faster than their increase in the roller mill due to a decrease in deformation of grains. In the range of gaps between the rollers of the flaking mill from 0.8 to $1.6 \mathrm{~mm}$, there is an intensive increase in the yield of small products in the roller mill much faster than their output decreases during flattening. 


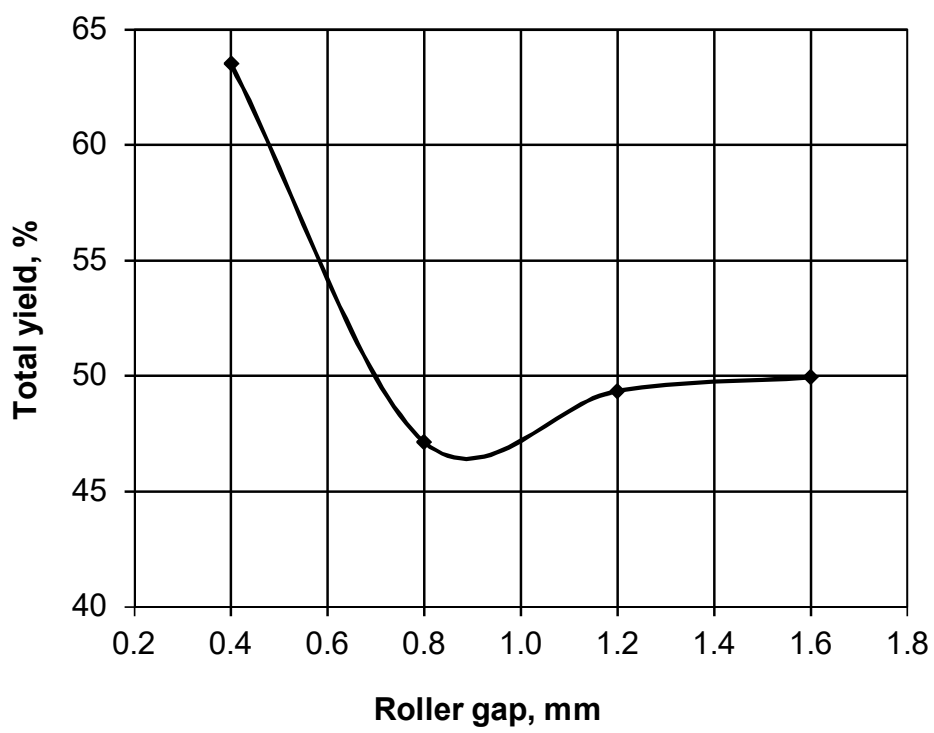

Figure 4. Total product of intermediate grinding products after flattening and grinding in the roller mill (in total)

In addition, the nature of the curve of the total product of the two systems was influenced by the size of the particles obtained after flattening, since the distance between the rollers of the roller mill remained unchanged, and the products of flattening with an increase in the distance between the rollers of the flaking mill increased their overall dimensions.

From both series of studies, the following conclusions can be drawn: if we take $1.4 \mathrm{~mm}$ as the optimal gap between the rollers of the flaking system, the total product of intermediate grinding products in the roller mill varies within $2.9 \%$ depending on the organization of the flattening and grinding process. Based on the results of research, it is impossible to give preference to the first or second method of grinding flattened wheat, since there are no significant differences between them with a gap value between the rollers of the flaking mill of $1.4 \mathrm{~mm}$.

\section{Analysis of granulometric characteristics of grinding products}

To clarify the effect of the flattening process on the product of individual fractions of grinding products, granulometric characteristics of grinding products were investigated, provided that large products were crushed, and small products were previously isolated in the aspiration channel.

The differential curves in Figure 5 are predominantly the same. It is noteworthy that when grinding whole grain (control sample) in the roller mill, in the particle size range from $90 \mu \mathrm{m}$ to $400 \mu \mathrm{m}$, the product of grinding products is greater than for flattened wheat grain. And from $400 \mu \mathrm{m}$ to $1000 \mu \mathrm{m}$ product of products is less than for products that have undergone flattening. For products that have passed flattening, regardless of the size of the gap between the rollers of the flaking mill, there is a smaller product of small fractions (less than 400 microns) and vice versa an increase in the product of large fractions. 


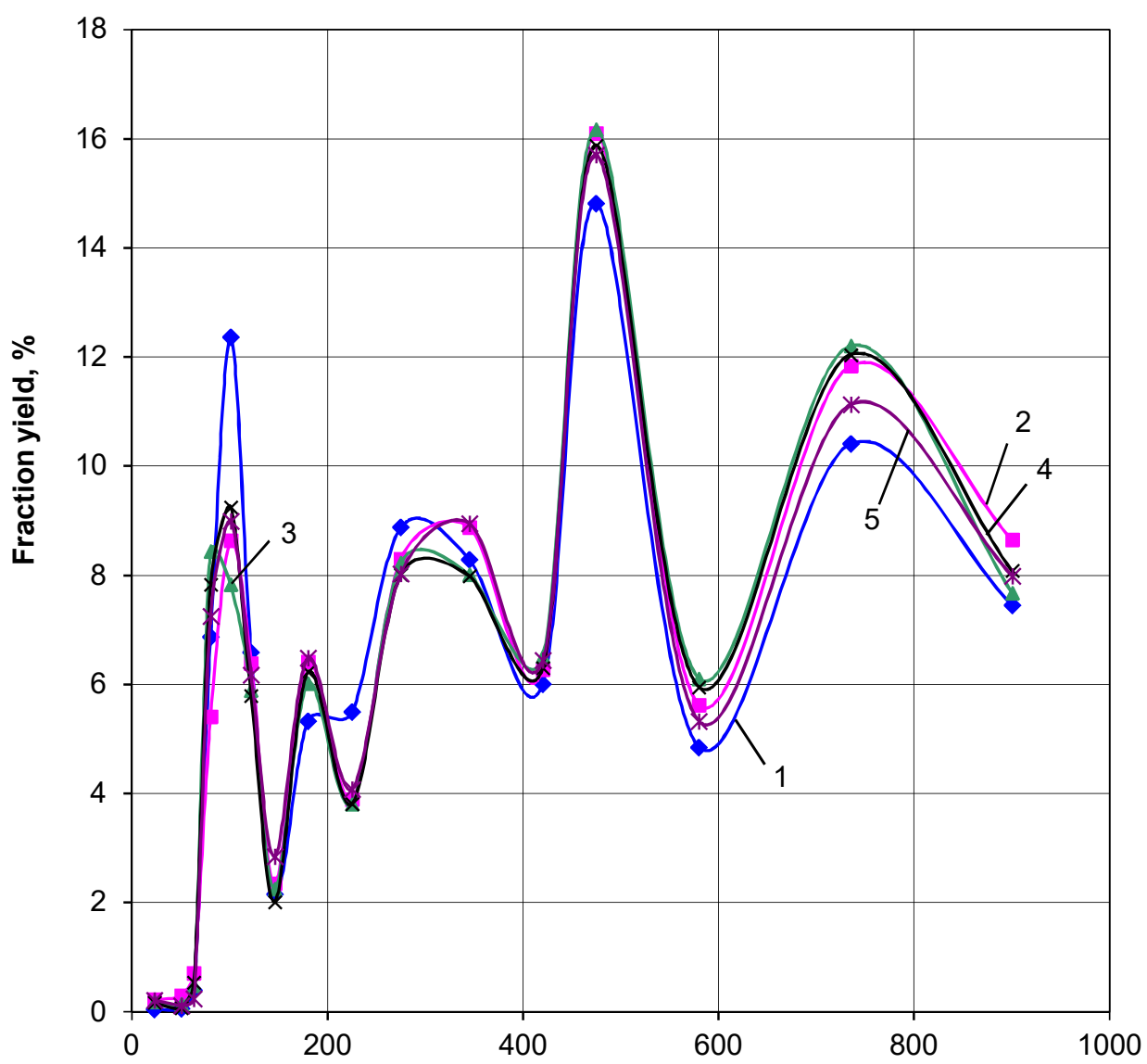

Particle size, $\mu \mathrm{m}$

Figure 5. Differential distribution curves of intermediate grinding products after the roller mill (with selected small products after flattening):

1 - control sample (whole grain);

2 - value of the distance between the rollers of the flaking system is $0.4 \mathrm{~mm}$;

3 - value of the distance between the rollers of the flaking system is $0.8 \mathrm{~mm}$;

4 - value of the distance between the rollers of the flaking system is $1.2 \mathrm{~mm}$;

5 - distance between the rollers of the flaking system is $1.6 \mathrm{~mm}$.

From the results obtained, it can be concluded that large fractions are more crushed and moved to smaller ones when grinding whole grain under unchanged modes of operation of the roller mill.

Figure 5 shows that the output of individual fractions of intermediate grinding products has an uneven distribution in the total mass of the product, the differential curves are polymodal, as evidenced by the presence of five maximums in all curves. In fractions with the largest number of particles, the curve shows the maximum, and in the absence of particles, 


\section{— Food Technology —}

the curve decreases to zero. The uneven distribution of particles in the mixture can be explained by the heterogeneity of the strength of the wheat endosperm, as well as the uneven efforts applied to particles during grinding (Chornyi et al., 2021).

Integral curves are less sensitive to changes in granulometric composition of product fractions than differential curves and are the preferred way to graphically analyze granulometric composition data (Chornyi et al., 2021).

The integral distribution curves of wheat grain grinding products under different conditions have an S-shaped view (Lyu et al., 2020) and are shown in Figure 6.

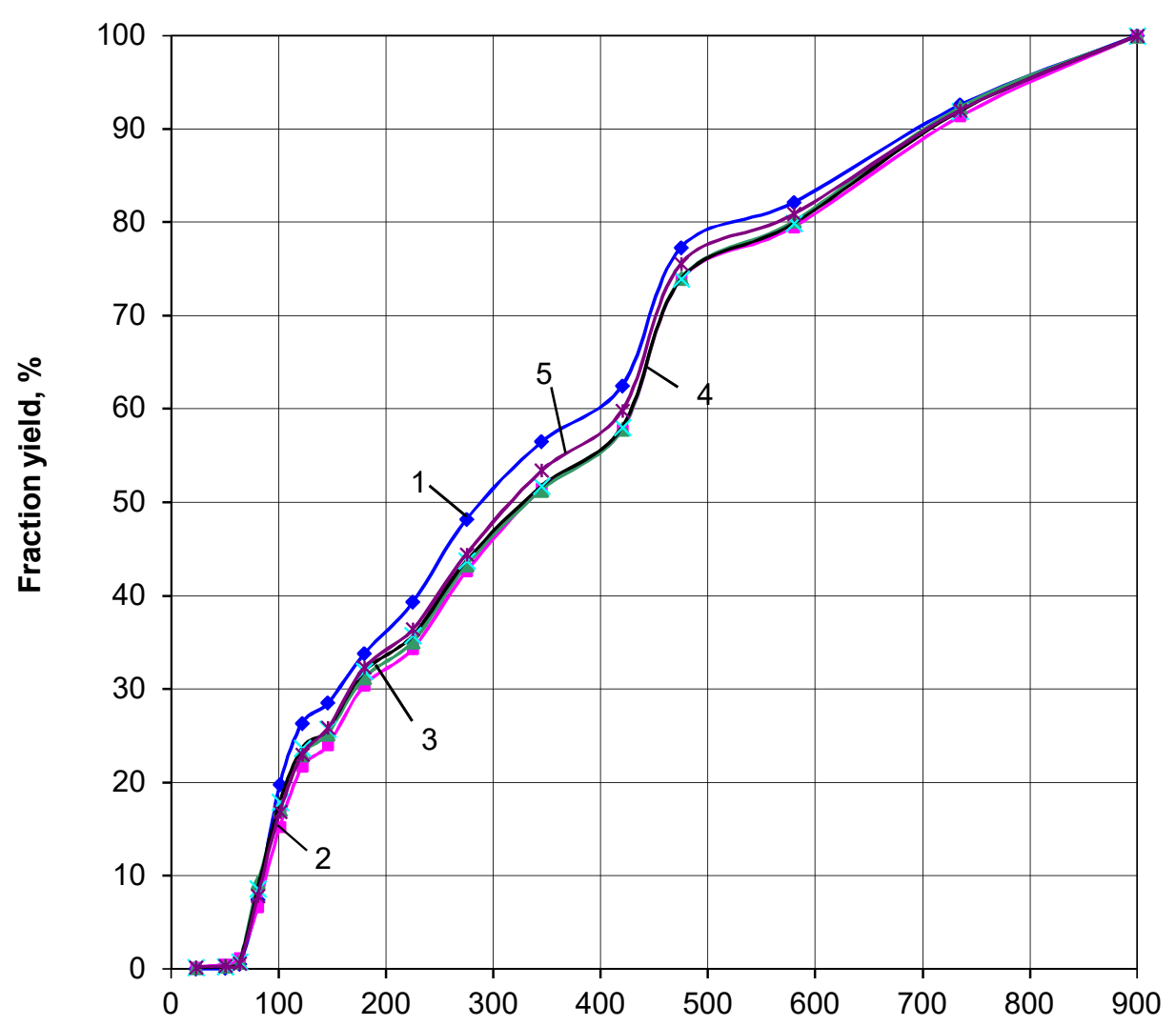

Particle size, $\mu \mathrm{m}$

Figure 6. Integral particle distribution curves of intermediate grinding products after the roller mill (with small products isolated after flattening):

1 - control sample (whole grain);

2 - value of the distance between the rollers of the flaking system is $0.4 \mathrm{~mm}$;

3 - value of the distance between the rollers of the flaking system is $0.8 \mathrm{~mm}$;

4 - value of the distance between the rollers of the flaking system is $1.2 \mathrm{~mm}$;

5 -distance between the rollers of the flaking system is $1.6 \mathrm{~mm}$. 
Analysis of integral curves showed that the largest yield of individual fractions of products was observed when grinding in the roller mill of the control sample, that is, the whole grain. Based on these integral curves, it can be concluded that in order to achieve a greater product of individual fractions of grinding products, it is necessary to adjust the distance between the rollers of the roller mill by increasing the total yield of grinding products.

The greater yield of individual fractions of products during grinding in the roller mill of the whole grain is explained by the fact that the wheat was not subjected to additional deformations and therefore, with a constant gap value between the rollers of the roller mill, greater grinding forces on individual grains were reflected, which gave a greater yield of individual fractions of products. Flattened grains, on the contrary, changed their overall dimensions and therefore, the rollers of the roller mill had less effect on the deformed grains, which led to a decrease in the yield of individual fractions of grinding products. The greater the gap between the rollers of the flaking mill, the greater the yield of fine fractions obtained in the roller mill. The obtained integral curves have a similar appearance to the integral curves obtained by Campbell G.M. and its collaborators (Campbell et al., 2007; Fang et al.,2003; Galindez-Najera et al., 2014; Galindez-Najera et al., 2016), which allows us to use the mathematical apparatus for their description, which was developed by G.M. Campbell.

\section{Conclusions}

Studies have confirmed the exponential dependence of the yield of intermediate products of flattening on the distance between the rollers of the flaking mill.

It is established that the modes of grinding of flattened grain in the roller mill and the shredded system depend on the mode of grain flattening in the flaking mill. The optimal distance between the rollers of the flaking mill is $1.4 \mathrm{~mm}$. At this distance between the rollers of the flaking mill, the highest yield of intermediate products of grinding is observed in the roller mill of I shredded system.

The total yield of intermediate products after flattening and grinding in the roller mill I shredded system in the absence of intermediate separation of flattening products increases $2.9 \%$ more than under similar conditions for the separation of these products.

Particle size analysis showed that the differential curves are polymodal in nature with five maxima. When grinding rolled wheat, more large products are formed than when grinding whole wheat grain.

\section{References}

Afanasj'ev V.A., Ostrykov A.N., Manujlov V.V. (2018), Yssledovanye processa plbshhenyja zerna jachmenja. In: VII international scientific and practical conference, Voronezh, RF, pp. 234-238.

Campbell G.M., Fang C., Muhamad, I.I. (2007), On predicting roller milling performance VI: Effect of kernel hardness and shape on the particle size distribution from first break milling of wheat, Food and Bioproducts Processing, 85, pp. 7-23.

Chornyi V., Kharchenko Y., Mysiura T., Popova N., Zavialov V. (2021), Investigation of particle size distribution of grinded amber by electropulse discharges in a liquid medium, Archive of Mechanical Engineering, 68(3), pp. 337-348. 
Deineko V.A., Pryshchiepova Y.M. (2012), Mathematical modeling of power of roller crusher of grain, Ukrainian Food Journal, 1(3), pp.4049

Dmitruk, E., Vereschinskii, O., Kharchenko, Y. (2013), Efficiency increase the milling systems in the bread baking wheat grindings, Ukrainian Food Journal, 2(2), pp. 163168.

Dziki D., Cacak-Pietrzak G., Mis A., Jonczyk K., Gawlik-Dziki U. (2012), Influence of Wheat Kernel Physical Properties on the Pulverizing Process, Journal Food Science and Technology, 51(10), pp. 2648-2655.

Fang C., Campbell G. M. (2003), On predicting roller milling performance IV: Effect of roll disposition on the particle size distribution from first break milling of whea, Journal of Cereal Science, 37, pp. 21-29.

Fistes, A. Z., Vukmirovic, D. M. (2009), Reduction of fheat middlings using a conventional and eight-roller millings systems, $A P T E F F, 40$, pp. 25-34.

Galindez-Najera S. P., Campbell G. M. (2014), Modeling First break Milling of Debranned Wheat Using the Bouble Normalized Kumaraswamy Breakage Function, Cereal Chemistry, 91(6), pp. 533-541.

Galindez-Najera S.P., Choomjaihan P., Barron C., Lullien-Pellerin V., Campbell G.M. (2016), A compositional breakage equation for wheat milling, Journal of Food Engineering, 182, pp. 46-64.

ISO (2009a), 712:2009(E), Cereals and cereal products. Determination of moisture content - Reference method, International Organization for Standardization, Geneva.

ISO (2009b), 7971-3:2009(E), Cereals - Determination of bulk density, called mass per hektolitre - Routine method, International Organization for Standardization, Geneva.

ISO (2010), 520:2010. Cereals and pulses - Determination of the mass of 1000 grains, International Organization for Standardization, Geneva.

Kharchenko Y., Sharan A., Chornyi V., Yeremeeva O. (2018), Effect of technological properties of pea seeds and processing modes on efficiency of its dehulling, Ukrainian Food Journal, 7(4), pp. 589-604.

Kharchenko Y., Sharan A., Yeremeeva O., Novak L. (2017), Yield of intermediate products in the drought process of wheat milling, Ukrainian Food Journal, 6(4), pp. 603-617.

Kharchenko Y.I., Perehuda M.A., Shnipko I.P. (2015), Granulometric composition of intermediate grinding products during two-stage grinding of wheat grain in laboratory conditions, Grain storage and processing, 6-7, pp. 62-64.

Kharchenko Y.I., Perehuda M.A., Ruban I.S. (2016), Flaking wheat grain in laboratory conditions, Grain storage and processing, 1, pp. 58-60.

Lyu F., Thomas M., Hendriks W.H., van der Poel A.F.B. (2020), Size reduction in feed technology and methods for determining, expressing and predicting particle size: A review, Animal Feed Science and Technology, 261. pp. 1-20.

Morhun V.A., Zhyhunov D.A., Davyidov R.S. (2010), Comparative analysis of some structures of the croup formation process, Grain storage and processing, 12, pp. 29-33.

Mousia Z., Edherly S., Pandiella S. S., Webb C. (2004), Effect of Wheat Pearling on Flour quality, Food Research International, 34, pp. 449-459.

Netrebsky, A.A. (2006), Intensification of grain grinding, Odesa.

Odegov V. A., Soboleva N.N., Zabolockykh I.U. (2004), Results preliminary studies of a two-stage grain conditioner, Improvement of operational agricultural energy indicators, 3, pp. 64-68.

Perekopskyi A.N. Baranov L.N. (2004), Formation of technological schemes for the production of feed by crushing and preserving grain, Technology and technical means of mechanized production of crop and livestock products, 76, pp. 71-74. 
Shutenko Y.I., Davyidov R.S. (2014a), Complex influence of modes and structure of the stage of croup formation on its efficiency, Scientific works ONAFT, 46, pp. 11-16.

Shutenko, Y. I., Davyidov, R. S. (2014b), Pre-grinding in small-scale factories, Cereals and compound feed, 2(54), pp. 22-25.

Stefan E.-M., Voicu G., Constantin G.-A., Stoica D. (2013), Variation of crushing characteristics by compression of wheat seeds, Metalurgia International, 18(5), pp. 7177.

Voicu G., Biris S., Stefan E., Constantin G.-A., Ungureanu N. (2013), Grinding characteristics of wheat in industrial mills. In: Food Industry, IntechOpen, pp. 323-354.

Voicu G., Tudosie E., Ungureanu N., Constantin G.-A. (2013), Some mechanical characteristics of wheat seeds obtained by uniaxial compression tests. U.P.B., Sci. Bull., Series D, 75(4), pp. 265-278.

Warechowska, M., Markowska, A., Warechowski, J., Mis, A., Nawrocka, A. (2016), Effect of tempering moisture of wheat on grinding energy, middlings and flour size distribution and gluten and dough mixing properties, Journal of Cereal Science, 69, pp. 306-312. 